\title{
Multitest media for rapid identification of Proteus species with notes on biochemical reactions of strains isolated from urine and pus
}

\author{
C. T. HUANG \\ From the Department of Pathology and Bacteriology, University of Hong Kong
}

SYNOPSIS Two 'multitest' 1 media for biochemical classification of the genus Proteus into species were developed. The species so determined were checked with conventional methods. Results show that these media were useful for rapid identification of species. The biochemical reactions of four Proteus species isolated from clinical specimens as tested by conventional methods are reviewed and the occurrence of some atypical strains is described.

The classification of the genus Proteus into four species, namely, Proteus vulgaris, $\boldsymbol{P}$. mirabilis, $\boldsymbol{P}$. rettgeri, and $P$. morganii, was proposed by Rustigian and Stuart (1945) and has hitherto been widely accepted (Ewing, 1958; Topley and Wilson, 1964; Cowan and Steel, 1965). Although $P$. inconstans has appeared classified under Proteus in the seventh edition of Bergey's Manual (Breed, Murray, and Smith, 1957), Ewing (1958) suggested that this species should be kept in the genus Providence because of its negative urease activity. All Proteus species decompose urea, deaminate phenylalanine to phenylpyruvic acid, and may swarm in soft agar. Species classification is mainly based on further biochemical reactions, such as fermentation of maltose and mannitol, hydrogen sulphide and indole production, ability to utilize citrate, liquefaction of gelatin, and positive orithinic decarboxylase activity (Ewing, Suassuna, and Suassuna, 1960). However, in routine bacteriological diagnosis the identification of Proteus into species is not universally practised because of time and labour. Positive cultures are either reported as 'Proteus species' or ' $B$. proteus' without further discrimination. With the recent development of drugs for the treatment of urinary tract infections of Gram-negative rods, for example, ampicillin and nalidixic acid, it was found that the penicillinase-negative strains of $\boldsymbol{P}$. mirabilis were often sensitive to ampicillin (Barber and Garrod, 1963) whereas the other species were generally resistant to it. A rapid recognition of the species, therefore, bears some importance not only in the

The term 'multitest' was coined by Cowan and Steel (1965).

Received for publication 24 June, 1966. additional choice of drugs for routine sensitivity tests but also in epidemiological investigation of hospital cross-infection due to this genus. Although serological typing is a more reliable means for epidemiological study, for the genus Proteus no satisfactory serological typing has been described (Rustigian and Stuart, 1943 and 1945; Topley and Wilson, 1964) and biochemical typing is still a useful method for classification of this genus into species. Based on the biochemical reactions of Proteus already described (Rustigian and Stuart, 1945; Cook, 1948; Kauffmann, 1954), a set of two-tube 'multitest' media has been devised. With them, the four species of Proteus once screened for urease activity can be sorted out in less than 24 hours.

\section{MATERIALS AND METHODS}

The composition of the two multitest media was based on the biochemical reactions of Proteus species summarized in Table I. Their formulae are as follows: MEDIUM A

Lab-lemco beef extract ............. $3 \mathrm{~g}$.

Sodium chloride ............... $5 \mathrm{~g}$.

Bacto peptone $\ldots \ldots \ldots \ldots \ldots \ldots 10 \mathrm{~g}$.

Mannitol .................... $10 \mathrm{~g}$.

Ferrous sulphate $\ldots \ldots \ldots \ldots \ldots \ldots, \mathbf{0} \cdot \mathbf{2} \mathbf{g}$.

Sodium thiosulphite $\ldots \ldots \ldots \ldots \ldots \ldots, 0.3 \mathrm{~g}$.

Agar ...................

Indicator mixture $\ldots \ldots \ldots \ldots \ldots \ldots .26 .5 \mathrm{ml}$.

Distilled water .............. 1,000 ml.

Adjust $p \mathrm{H}$ to 7.6

The Singer indicator mixture (Singer, 1950) was used. It gave much better differentiation between the results of alkaline growth and blackening due to $\mathrm{H}_{2} \mathrm{~S}$ production in medium $\mathrm{A}$. The medium was dispensed into $100 \times$ 
$10 \mathrm{~mm}$. test tubes in 2 to $3 \mathrm{ml}$. amounts. It was sterilized by autoclaving at $10 \mathrm{lb}$. pressure per sq. in. for 15 minutes and was allowed to set in the form of a slope with deep butt. Inoculation was made by smearing the slant and then stabbing the butt with the inoculum.

\section{MEDIUM B}

Lab-lemco beef extract .......... $3 \mathrm{~g}$.

Bacto peptone $\ldots \ldots \ldots \ldots \ldots \ldots \ldots 10 \mathrm{~g}$.

Bacto tryptone $\ldots \ldots \ldots \ldots \ldots \ldots \ldots 10 \mathrm{~g}$.

Sodium chloride............ 5 g.

Maltose .................

Oxoid gelatin granules $\ldots \ldots \ldots \ldots 120 \mathrm{~g}$.

Indicator mixture .............

Distilled water ...........

Adjust $p \mathrm{H}$ to $7 \cdot 6$

For uniformity the same indicator mixture was used in medium B. The medium was dispensed and sterilized in the same manner as for medium $A$, except that it was allowed to set in a vertical position and was inoculated by stabbing only. Immediately after inoculation, a filter paper soaked in Ehrlich reagent and dried was suspended above medium $B$ and held by the cotton plug for indole testing.

All cultures were incubated at $37^{\circ} \mathrm{C}$. for 18 to 24 hours. Cultures in medium B were placed in the refrigerator at 4 to $10^{\circ} \mathrm{C}$. for at least 30 minutes so that the gelatin might set. The media can be kept at room temperature (20 to $25^{\circ} \mathrm{C}$.) for a month.

Proteus cultures classified by medium A and medium B were subjected to biochemical tests in conventional media for confirmation. These included the urease test in the strongly buffered urea medium of Stuart, van Stratum, and Rustigian 1945); the phenylpyruvic acid (P.P.A.) test in phenylalanine medium of Edwards, Fife, and Ewing 1961); sugar fermentation reactions in $10 \%$ sugar medium containing Andrade's indicator and Durham's tube; indole production in $1 \%$ peptone water tested by Ehrlich reagent ; citrate utilization in Simmon's citrate medium; gelatin liquefaction in $2 \mathrm{ml}$. nutrient broth containing an Oxoid charcoal gelatin disc; and hydrogen sulphide production in nutrient agar with a paper strip soaked in a saturated solution of lead acetate.

\section{RESULTS}

The uninoculated media were yellowish green. When no fermentation takes place in medium $A$, the alkaline growth of Proteus would cause the slant to become purplish and then dark blue and the butt bluish green. Whereas, in medium B, it was bluish green initially on the top then the bluish green colour gradually extended to the bottom. With positive fermentation, the media were yellowish; however, the yellow slant of medium A may subsequently become purplish due to alkaline growth of $P$. rettgeri in the presence of oxygen. Blackening of the butt of medium $\mathrm{A}$ indicated production of $\mathrm{H}_{2} \mathrm{~S}$ and partial or complete absence of setting of gelatin in medium B indicated liquefaction. Proteus vulgaris (N.C.T.C. 4363), P. mirabilis (N.C.T.C. 5887), P. rettgeri (N.C.T.C. 7475), and P. morganii (N.C.T.C. 235) obtained from the National Collection of Type Cultures, England, were inoculated into medium A and medium $B$ as described. The observed results correlated completely with the expected results (Table I). The results were also confirmed by testing these N.C.T.C. strains in conventional medium. Both medium A and medium B supported good growth of all Proteus species. As small an inoculum as a loopful from a diluted suspension of a 24-hour broth culture containing about 2,000 organisms per $\mathrm{ml}$. of the four N.C.T.C. strains could yield clear-cut results after overnight incubation.

Upon testing 636 strains of Proteus isolated from 7,659 specimens of urine and pus in the 'multitest' media, 52 strains of $P$. vulgaris, 469 strains of $P$. mirabilis, 72 strains of $P$. rettgeri, and 43 strains of $P$. morganii were classified in a 10 -month period. Isolation of Proteus from sputum, blood, and faeces was not extensive enough to be included in this series. The percentage of distribution of the four

TABLE I

Expected Reaction

\begin{tabular}{ll}
\hline Mannitol & $\mathrm{H}_{2} \mathrm{~S}$ \\
Fermenta- & Prod
\end{tabular}

Fermenta- Production

tion

vulgaris

(N.C.T.C. 4363)

mirabilis

(N.C.T.C. 5887)

rettgeri

(N.C.T.C. 7475)

morganii

(N.C.T.C. 235)

$\begin{array}{ccc}- & + & \text { Purple (-) Yes } \\ - & + & \text { Purple (-) Yes } \\ + & - & \text { Yeliow (+) No } \\ - & - & \text { Purple (-) No }\end{array}$

Expected Reaction

\begin{tabular}{ll} 
Observed & Reaction \\
\hline Colour & Blackening \\
of & of \\
Slant & Butt
\end{tabular}

$\begin{array}{ll}\text { Maltose } & \text { Gelatin } \\ \text { Fermenta- } & \text { Liquef }\end{array}$

Fermenta- Liquefaction Production tion

$+\quad \pm$

$\pm \quad+$

$\stackrel{ \pm}{\text { (slow) }}$

$+\quad-$

-

- 
species indicated in Table II showed that $P$. mirabilis was the prevailing species. This finding is closely in accord with those of other authors (Cook, 1948; Rustigian and Stuart, 1945; Keating, 1956; Kippax, 1957). The discrimination of the isolates into species was later confirmed by conventional methods of biochemical testing.

TABLE II

DISTRIBUTION OF PROTEUS SPECIES ISOLATED FROM URINE AND PUS

\begin{tabular}{|c|c|c|c|}
\hline & \multirow{2}{*}{$\begin{array}{l}\text { Urine } \\
\text { Number of } \\
\text { Strains } \\
\text { Isolated }\end{array}$} & \multirow{2}{*}{$\begin{array}{l}\text { Pus } \\
\text { Number of } \\
\text { Strains } \\
\text { Isolated }\end{array}$} & \multirow{2}{*}{$\begin{array}{l}\text { Total } \\
\text { No. of } \\
\text { Strains }\end{array}$} \\
\hline & & & \\
\hline $\begin{array}{l}P . \text { vulgaris } \\
P . \text { mirabilis } \\
P . \text { rettgeri } \\
P . \text { morganii } \\
\text { Total }\end{array}$ & $\begin{array}{c}34(7 \%) \\
344(73 \%) \\
68(14 \%) \\
26(6 \%) \\
472\end{array}$ & $\begin{array}{c}18(11 \%) \\
125(76 \%) \\
4(3 \%) \\
17(10 \%) \\
164\end{array}$ & $\begin{array}{c}52(8 \%) \\
469(74 \%) \\
72(11 \%) \\
43(7 \%) \\
636\end{array}$ \\
\hline
\end{tabular}

The urine and pus were primarily inoculated into blood agar (containing $1.2 \%$ agar) and MacConkey plates. Organisms which produced lactose-negative colonies on the latter, no matter whether they swarmed or not on the blood agar, were screened for urease activity by picking the lactose-negative colonies and inoculating them into modified Kohn's medium 1 (vide infra). Urease-positive cultures within six to eight hours' incubation at $37^{\circ} \mathrm{C}$. were subinoculated into media $\mathrm{A}$ and $\mathrm{B}$ for classification. If a sensitivity test were required, it was carried out at the same time; thus, the results of both tests could be reported overnight after isolation. The picking of swarming growth from the margin of a soft agar plate and directly inoculated into medium $\mathbf{A}$ and medium B is not advised. Despite the question of purity of the spreading growth in the presence of other group of organisms, not uncommonly two species of Proteus may be found and swarmed in the same plate.

A set of modified Kohn's two-tube media (Kohn, 1954) has been used for many years in this laboratory for preliminary isolation of the SalmonellaShigella group from hospital specimens. Mannitol in tube 1 was replaced by lactose, $\mathrm{H}_{2} \mathrm{~S}$ testing reagents and salicin were omitted in tube 2, and phenol red in concentration of $0.03 \mathrm{~g}$. per litre was the indicator used. Since suspicious cultures of the SalmonellaShigella group can easily be discriminated by subsequent slide-agglutination tests with polyvalent sera, the omission of these reagents greatly reduced the cost, especially when large quantities of materials were handled daily. When the modified Kohn's media were used in conjunction with medium $\mathrm{A}$ and medium $B$ described in this paper, a combination of 10 tests in four tubes could be obtained. Thus, tests for urease activity, glucose, lactose and sucrose fermentations, motility, and indole production can be revealed by the modified Kohn's medium, and maltose and mannitol fermentation and $\mathrm{H}_{2} \mathrm{~S}$ and gelatinase production by medium A and medium B. Since different indicators were used in the two sets of media, confusion through mishandling could be avoided.

Apart from certain discrepancies, the results of biochemical tests in conventional media presented in Table III are in general accord with the work of previous workers (Rustigian and Stuart, 1945; Cook, 1948; Ewing et al., 1960; Keating, 1956). Only 133 isolates of $\boldsymbol{P}$. mirabilis were tested in this way, whilst all strains of the other species were studied as required. Thus, all Proteus strains sorted out as described were urease-positive, P.P.A. positive, did not attack lactose, and produced very small amounts of gas or no gas in fermentable sugars. Of 52 strains of $P$. vulgaris, all fermented glucose and maltose promptly; only 51 fermented sucrose and 50 fer-

TABLE III

BIOCHEMICAL REACTIONS OF PROTEUS SPECIES AS TESTED BY CONVENTIONAL METHOD

\begin{tabular}{|c|c|c|c|c|c|c|c|c|c|c|c|c|c|}
\hline \multirow{2}{*}{$\begin{array}{l}\text { No. of } \\
\text { Strains } \\
\text { Tested }\end{array}$} & \multirow{2}{*}{$\begin{array}{l}\text { Urease } \\
\text { Positive } \\
\text { in } \\
24 \text { Hours }\end{array}$} & \multirow{2}{*}{$\begin{array}{l}\text { P.P.A. } \\
\text { Positive } \\
\text { in } \\
24 \text { Hours }\end{array}$} & \multicolumn{6}{|c|}{ Fermentation of Sugar in 14 Days } & \multicolumn{2}{|c|}{$\begin{array}{l}\text { Indole Production } \\
\text { in } 48 \text { Hours }\end{array}$} & \multirow{2}{*}{$\begin{array}{l}\text { Citrate } \\
\text { Positive } \\
\text { in } \\
14 \text { Days }\end{array}$} & \multicolumn{2}{|c|}{$\begin{array}{l}\mathrm{H}_{2} \mathrm{~S} \text { Production } \\
\text { in } 48 \text { Hours }\end{array}$} \\
\hline & & & Glucose & Lactose & Maltose & $\begin{array}{l}\text { Man- } \\
\text { nitol }\end{array}$ & Sucrose & Xylose & $\begin{array}{l}\text { In } \\
\text { Peptone } \\
\text { Water }\end{array}$ & $\begin{array}{l}\text { With } \\
\text { Test } \\
\text { Paper }\end{array}$ & & $\begin{array}{l}\text { With } \\
\text { Lead } \\
\text { Acetate } \\
\text { Paper }\end{array}$ & $\begin{array}{l}\text { In } \\
\text { Medium } \\
A\end{array}$ \\
\hline
\end{tabular}

Disc

\section{P. vulgaris}

52

52

52

52

0

52

0

50

52

15

mirabilis

133

133

133

133

33

4

4

1

52

50

P. rettgeri

72

P. morganii

43

72

72

72

0

72

21

0

72

37

43

0

0

0

2

$0 \quad 43$

43

43

43


mented xylose within 14 days. Except for two strains, all produced blackening in medium $\mathrm{A}$; but these negative strains blackened lead acetate paper. Only 26 strains liquefied gelatin in medium B within 14 days and the reaction was generally slow. This result was checked by charcoal gelatin discs. As indicated in Table III, less than one-third of $\boldsymbol{P}$. vulgaris strains reddened indole-testing paper within 48 hours in medium A, but all were indole-positive when grown in peptone water and tested by Ehrlich's reagent. It shows that the indole-testing paper is relatively less sensitive. Keating (1956) and Kippax (1957) had isolated maltose-positive, indole-negative strains of Proteus from hospital specimens. This intermediate type was not found in this series.

All 133 strains of $\boldsymbol{P}$. mirabilis fermented glucose and xylose with acid and a slight amount of gas. Sucrose fermentation was irregular and slow. Forty strains fermented sucrose within 10 days with slight change of colour of the indicator only, and the rest were negative after 14 days. Eighty-seven strains could utilize citrate. Strong $\mathrm{H}_{2} \mathrm{~S}$ production and gelatinase activity were unique characters of $\boldsymbol{P}$. mirabilis. There were, however, four indole-positive strains with characters typical of $P$. mirabilis. To ensure that there was no contamination, the isolates had been plated onto MacConkey plates and several single colonies from each culture were re-tested. The results persisted and therefore they were considered as indole-positive variants of $P$. mirabilis.

All 72 strains of $P$. rettgeri were anaerogenic in glucose and mannitol fermentation. Fermentation of sucrose by $P$. rettgeri was variable and delayed and none of them fermented xylose. Citrate utilization was not a unique character of $P$. rettgeri, because only 43 out of 72 strains were citrate-positive within the prescribed period of observation. Though none showed blackening in medium $A$, the $\mathrm{H}_{2} \mathrm{~S}$ production of 13 strains could be detected within 48 hours by a lead acetate paper technique.

Forty-three $\boldsymbol{P}$. morganii strains fermented glucose promptly. Among them there were 12 anaerogenic strains. The other sugars were not attacked, though two strains showed very slight acid reaction in sucrose fermentation after five to seven days' incubation. None of the $P$. morganii strains blackened medium $\mathrm{A}$, which contained the same $\mathrm{H}_{2} \mathrm{~S}$ testing reagents as in Bacto TSI agar. However, when tested with lead acetate paper, all were positive. The results confirmed the observations of Ewing et al. (1960) and Rauss and Vörös (1959) who showed that lead acetate paper was a more sensitive indicator.

Contrary to the description maintained in Bergey's Manual that $\boldsymbol{P}$. vulgaris was rapid in gelatin liquefaction whereas $\boldsymbol{P}$. mirabilis was slow, all the strains of $\boldsymbol{P}$. mirabilis have much stronger gelatinase activity than those of $P$. vulgaris. Keating (1956) also found that most strains of $P$. mirabilis liquefied gelatin in two days whereas those of $P$. vulgaris mostly took seven days. The medium used, the size of the inoculum, and the strain tested certainly influence the result. For instance, Greene and Larks (1955), by employing a charcoal gelatin disc and a heavy inoculum, showed that $P$. vulgaris could liquefy gelatin in as short a time as two hours. Lautrop (1956) stated that calcium ions were essential for gelatinase production in some genera and that calcium-precipitating ions such as phosphates and oxidates seemed to inhibit gelatinase formation of many organisms. The results presented in Table III showed that $\boldsymbol{P}$. mirabilis is a more regular gelatinase producer and that the charcoal gelatin disc is a more sensitive indicator. Rustigian and Stuart (1945) mentioned that recent isolates liquefied gelatin more quickly than stock strains and that four of their stock cultures of $P$. vulgaris were gelatin-negative after incubation for 28 days. The results presented in Table IV are taken from another experiment which shows that strain difference is more important than the stock age of the isolate. $P$. vulgaris strain 233 was isolated and stocked in this laboratory for more than $\mathbf{1 0}$ years and yet its strong gelatinase activity was unaltered whereas a recent isolate, strain 101603, has very weak gelatinase activity. This experiment also shows that neither the size of the inoculum nor the source of the strain did ostensibly vary the result. Nonetheless, the slow gelatin liquefaction of $P$. vulgaris in medium B has not reduced the differential value of the 'multitest' media described, because maltose fermentation is a distinctive character of $\boldsymbol{P}$. vulgaris.

TABLE IV

COMPARISON OF GELATIN LIQLEFACTION OF $\boldsymbol{P}$. Vulgaris STRAINS

Number of Days Required to Liquefy Gelatin in

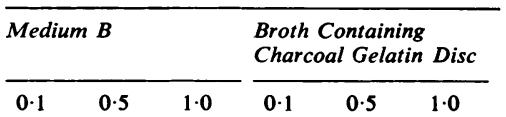

Size of Inoculum (ml.)

P. Vulgaris

\begin{tabular}{lrrrrrr}
\hline N.C.T.C. 4363 & 21 & 21 & 21 & 21 & 18 & 18 \\
101603 (urine) & 28 & 28 & 28 & 18 & 15 & 15 \\
233 (stool) & 21 & 7 & 4 & 6 & 6 & 6 \\
Pig (lymph-node) & 7 & 4 & 4 & 6 & 5 & 5 \\
Pig (stool) & 21 & 21 & 21 & 10 & 10 & 10
\end{tabular}

\section{DISCUSSION}

The combination of the testing reagents in media $A$ and $B$ was such that no reaction may hamper the reading of another. Urea cannot be incorporated 
into these media because the high $p H$ reaction resulting from rapid hydrolysis of urea would undermine the acid reaction from sugar fermentation. Maltose and mannitol were not incorporated together because it would leave $\mathrm{H}_{2} \mathrm{~S}$ production as the sole criterion to differentiate $\boldsymbol{P}$. vulgaris from $\boldsymbol{P}$. rettgeri. Difficulty arises, especially when a weak $\mathrm{H}_{2} \mathrm{~S}$-producing strain of $\boldsymbol{P}$. vulgaris is encountered. The combination of maltose with the $\mathrm{H}_{2} \mathrm{~S}$ testing reagent in medium $B$ is also undesirable because the intense blackening would mask the colour change due to maltose fermentation of $\boldsymbol{P}$. vulgaris. Since $\boldsymbol{P}$. rettgeri does not produce $\mathrm{H}_{2} \mathrm{~S}$ in medium $\mathrm{A}$, it therefore presents no problem.

Apart from the discrepancies in gelatin liquefaction of $\boldsymbol{P}$. vulgaris, the results obtained by conventional methods of biochemical testing were in general agreement with the findings of previous workers. Rustigian and Stuart (1943) had pointed out that anaerogenic fermentation of sugar was not a good criterion for discrimination of $P$. rettgeri. The existence of anaerogenic strains of the other species supported their view. That swarming cannot be relied upon for isolation of Proteus has been mentioned. Less than $50 \%$ of the isolates of $P$. morganii and $P$. rettgeri swarmed upon primary isolation. The importance of screening urease activity before inoculating the isolate into medium $A$ and medium $B$ is because the mannitol-negative Shigella subgroup A strains may be confused with weak $\mathrm{H}_{2} \mathrm{~S}$-producing $P$. vulgaris and the non-sugar fermenting Alcaligenes faecalis may complicate $P$. morganii. But all of them are urease-negative. Although some strains of the Klebsiella-Aerogenes group may be urease-positive, their fermentation of both maltose and mannitol in media A and $\mathbf{B}$ helps to discriminate them from Proteus, since none of the latter ferments both sugars.

Keating (1956) and Kippax (1957) reported atypical indole-negative, maltose-positive strains of $P$. vulgaris from hospital infections. Apart from the indole test, Keating's 'odd strain' resembled $P$. vulgaris, because it also fermented sucrose within two days. The four variant strains described in this paper resembled Kippax's atypical 2 strain. Transitional or intermediate biochemical groups frequently occur. The position of these strains remains to be deter- mined: since the difference is so slight from $P$. mirabilis, they are considered as indole-positive variants of this species. Xylose-positive variants of $P$. rettgeri and $P$. morganii as described by Kippax were, however, not encountered. Nevertheless, these intermediate strains, such as the atypical 1 and 2 strains of Kippax, can be detected by the 'multitest' media described in this paper. Since these intermediate strains occurred not infrequently in urine specimens of hospital patients, media $A$ and $B$ are therefore useful for tracing them in hospital infections. Furthermore, $P$. morganii has been incriminated to cause enteritis (Topley and Wilson, 1964) and this potential intestinal pathogen can also be conveniently tracked down during outbreaks by using these media.

Thanks are due to the Director of National Collection of Type Cultures, England, for providing the type strains of Proteus, and to Mr. M. F. Lau for technical assistance.

\section{REFERENCES}

Barber, M., and Garrod, L. P. (1963). Antibiotic and Chemotherapy. Livingstone, Edinburgh and London.

Breed, R. S., Murray, E. G. D., and Smith, N. R. (1957). In Bergey's Manual of Determinative Bacteriology, 7th ed., p. 365, edited by R. S. Breed et al. William and Wilkins, Baltimore.

Cook, G. T. (1948). J. Path. Bact., 60, 171.

Cowan, S. T., and Steel, K. J. (1965). Manual for the Identification of Medical Bacteria. Cambridge University Press, London.

Edwards, P. R., Fife, M. A., and Ewing, W. H. (1961). Publ. Hlth $L a b ., 19,85$.

Ewing, W. H. (1958). Int. Bull. bact. Nomencl., 8, 17.

W, W. H., Suassuna, I., and Suassuna, I.R. (1960). The Biochemical Reactions of the Genus Proteus. United States Dept. Health, Education and Welfare, Atlanta 22: Publ. Health Service, Communicable Disease Centre, Georgia.

—, Suassuna, I., and Suassuna, I. R. (1953). J. gen. Microbiol., 8, 397.

Greene, R. A., and Larks, G. G. (1955). J. Bact., 69, 224.

Kauffmann, F. (1954). Enterobacteriaceae, 2nd ed. Munksgaad, Copenhagen.

Keating, S. V. (1956). Med. J. Aust., 2, 168.

Kippax, P. W. (1957). J. clin. Path., 10, 211.

Kohn, J. (1954). J. Path. Bact., 67, 286.

Lautrop, H. (1956). Acta path. microbiol. scand., 39, 357.

Rauss, K., and Vörös, S. (1959). Acta microbiol. Acad. Sci. hung., 6 , 233.

Rustigian, R., and Stuart, C. A. (1943). Proc. Soc. exp. Biol. (N.Y.), 53, 241.

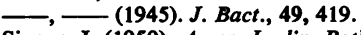

Singer, J. (1950). Amer. J. clin. Path., 20, 880.

Stuart, C. A., van Stratum, E., and Rustigian, R. (1945), J. Bact., 49, 437.

Topley and Wilson's Principles of Bacteriology and Immunty (1964). 5th ed., edited by G. S. Wilson and A. A. Miles. Arnold, London. 